\title{
The Atlantic multidecadal oscillation and its relation to rainfall and river flows in the continental U.S.
}

\author{
David B. Enfield \\ NOAA Atlantic Oceanographic and Meteorological Laboratory, Miami, Florida.
}

\author{
Alberto M. Mestas-Nuñez \\ Cooperative Institute for Marine and Atmospheric Studies, University of Miami, Miami, Florida.
}

Paul J. Trimble

South Florida Water Management District, West Palm Beach, Florida.

\begin{abstract}
North Atlantic sea surface temperatures for 1856-1999 contain a 65-80 year cycle with a $0.4{ }^{\circ} \mathrm{C}$ range, referred to as the Atlantic Multidecadal Oscillation (AMO) by Kerr [2000]. AMO warm phases occurred during 18601880 and 1940-1960, and cool phases during 1905-1925 and 1970-1990. The signal is global in scope, with a positively correlated co-oscillation in parts of the North $\mathrm{Pa}-$ cific, but it is most intense in the North Atlantic and covers the entire basin there. During AMO warmings most of the United States sees less than normal rainfall, including Midwest droughts in the 1930s and 1950s. Between AMO warm and cool phases, Mississippi River outflow varies by $10 \%$ while the inflow to Lake Okeechobee, Florida varies by $40 \%$. The geographical pattern of variability is influenced mainly by changes in summer rainfall. The winter patterns of interannual rainfall variability associated with El NiñoSouthern Oscillation are also significantly changed between AMO phases.
\end{abstract}

\section{Introduction}

Using a singular spectrum analysis on global surface temperature records since the $1850 \mathrm{~s}$, Schlesinger and Ramankutty [1994] identified a North Atlantic surface temperature oscillation with a period of 65-70 years and suggested that it arises from internal ocean-atmosphere variability. Andronova and Schlesinger [2000] conducted simulations of the observed global temperature using six models with varying combinations of external forcings due to anthropogenic (greenhouse) and solar variabilities plus injections of volcanic aerosols. The external forcings account for the nonlinear secular increase in temperatures but fail to reproduce the previously identified 65-70 year cycles that are manifested in global temperature data. The residual oscillation is likely a natural cycle mediated by ocean-atmosphere interactions that can't be reproduced by the simple climate/ocean model. Similar oscillations in a 60-110 year band are seen in paleoclimatic North Atlantic climate reconstructions dating at least to 1650 A.D. [e.g., Delworth and Mann, 2000]. In two independent, naturally forced integrations of the GFDL coupled ocean-atmosphere model,

Copyright 2001 by the American Geophysical Union.

Paper number 2000GL012745. 0094-8276/01/2000GL012745\$05.00
Delworth and Mann [2000] have reproduced the observed multidecadal patterns of variability. They demonstrate that in both the model and observations SST appears to carry the multidecadal signal and that the model evolution involves fluctuations in the intensity of the Atlantic thermohaline circulation. Consistent with this, Venegas and Mysak [2000] find a multidecadal mode of variability between observed sea ice concentration in the Greenland Sea and sea level pressure over high northern latitudes that is more or less synchronous with the AMO variability in SST.

Partly to distinguish it from wide-band variability associated with the atmospheric North Atlantic Oscillation (NAO), the long time scale oceanic phenomenon has recently been referred to as the Atlantic Multidecadal Oscillation (AMO) [Kerr, 2000]. While anthropogenic factors appear to have become dominant in the late 20th century, the ostensibly natural temperature swings of the AMO have alternately disguised and accentuated the secular trend. Considerable importance is now being placed on understanding and predicting this natural cycle so that it may be correctly accounted for in ongoing evolution assessments of greenhouse warming. It is also important to understand the effects of the AMO on the intensity and geographic coverage of interannual impacts such as those of El Niño-Southern Oscillation (ENSO). In this study we examine both the multidecadal and interannual behaviors of precipitation over the continental U.S. as they relate to the alternating phases of the oceanic AMO.

\section{Data and methods}

Our study is based on three data sets: an updated (18561999) version of the Kaplan et al. [1998] monthly reanalysis of global SST anomalies (SSTA), monthly rainfall over the continental United States summarized by climate divisions (1895-1999) [National Climatic Data Center], and (as independent hydrological checks) the records of Mississippi River outflow and the indirectly estimated inflow into Florida's Lake Okeechobee. These are compared to the appropriate area-weighted rainfall accumulations over the corresponding catchments. Because net runoff goes as the difference between rainfall and evapotranspiration (unavailable for our analysis) the comparisons with river flows were done by rescaling the basin rainfall totals to the variance and mean of the river flow data. We focus on the multidecadal character of the data sets by applying a ten-year running mean to 


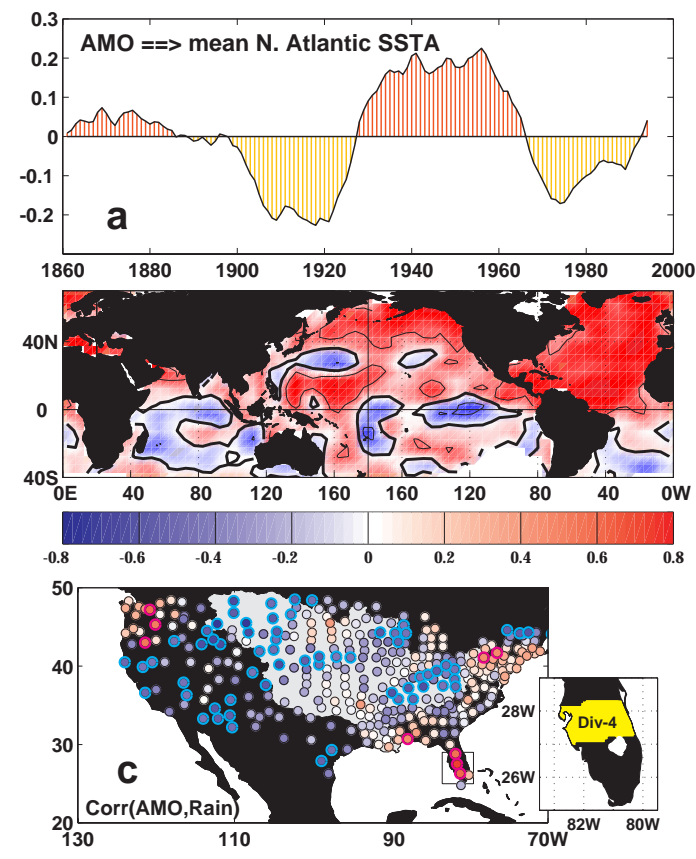

Figure 1. (a) AMO index: the ten-year running mean of detrended Atlantic SSTA north of the equator. (b) Correlation of the AMO index with gridded SSTA over the world ocean (all seasons). The thick contour is zero and thin contours denote the 95\% significance level. (c) Correlation of the AMO index with climate division rainfall with the Mississippi basin highlighted by light gray fill. The larger highlighted circles indicate correlations above the $90 \%$ significance level. Inset diagram to the right is a blow-up of Florida showing Lake Okeechobee and Florida climate division 4 . The colorbar applies to correlations in both panels.

linearly detrended time series of all the data. Quantitative comparisons between SSTA and rainfall-related variables are made using conventional linear correlation analysis. Due to the high degree of serial correlation in the smoothed time series, a specially designed Monte Carlo analysis based on the randomization of phases in the frequency domain was used to determine the significance of correlations [Ebisuzaki, 1997].
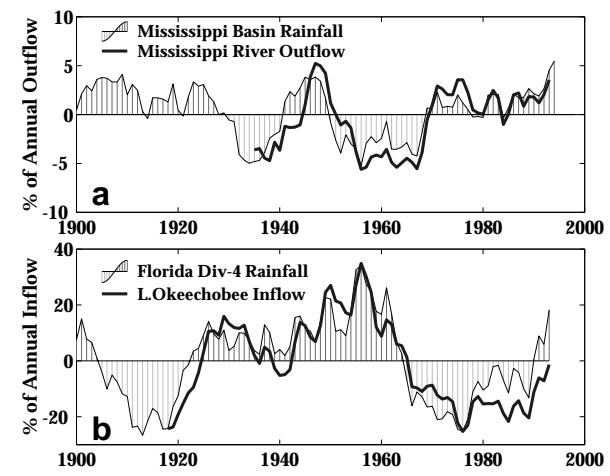

Figure 2. (a) Ten-year running means (all seasons) of Mississippi River outflow (heavy, solid) expressed as a percentage of the long term annual mean, and the area-weighted Mississippi basin rainfall (shaded departures), rescaled to the outflow. (b) As above but for Lake Okeechobee inflow and Florida division 4 rainfall.

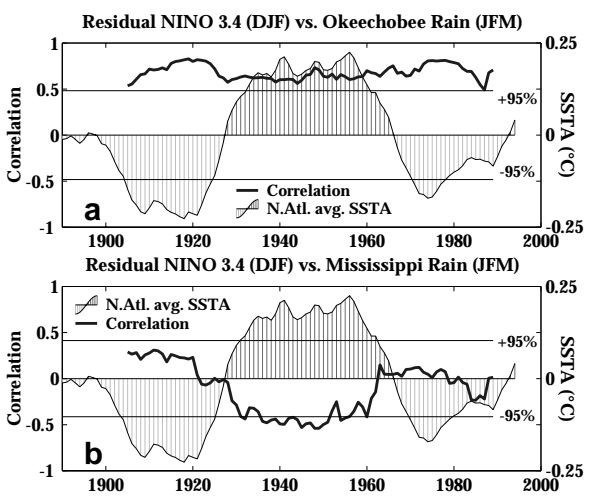

Figure 3. (a) Ten-year running mean of the AMO index (shaded departures) shown in comparison with the 20-year running correlation between the NINO-3.4 SSTA index for Dec.-Feb. and the unsmoothed Jan.-Mar. rainfall anomaly of Florida climate division 4 (heavy, solid). (b) As above, but for the area-weighted rainfall accumulation over the Mississippi basin.

\section{Slow changes associated with the AMO}

We index the AMO with a ten-year running mean of Atlantic SSTA north of the equator (Fig. 1a). The temporal variations reproduce the phases and periodicity previously ascribed to the AMO. The roughly $0.4^{\circ} \mathrm{C}$ peak-to-peak variations are larger than for comparable areas in all other oceans. The high correlations of this index with North Atlantic gridded SSTA (Fig. 1b) confirm that this is an effective index. This simple index is virtually identical to what one obtains by smoothing the first rotated (North Atlantic) EOF mode of Mestas-Nuñez and Enfield [1999, henceforth ME991.

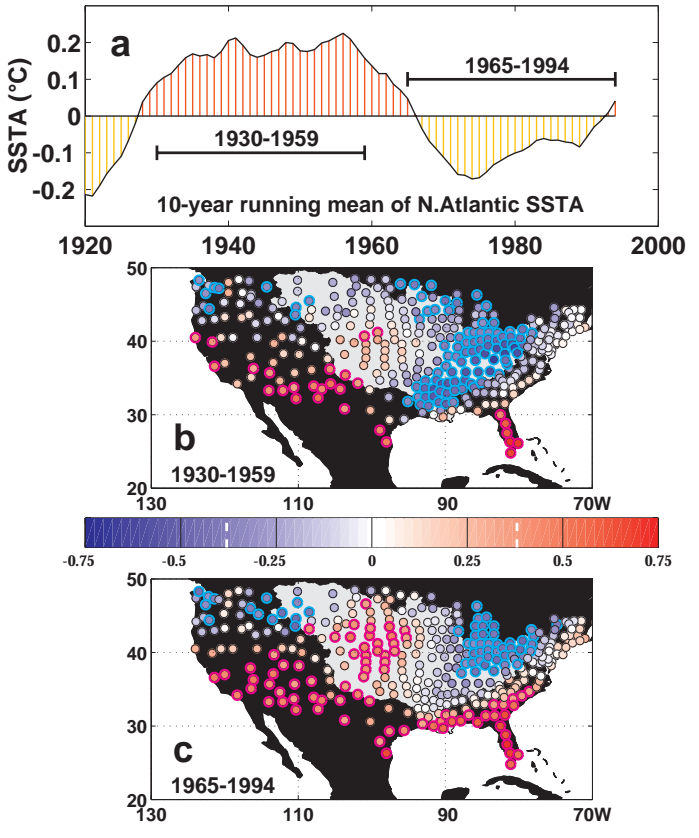

Figure 4. (a) The AMO index (1920-1995) showing two contrasting 30-year time periods for the calculation of ENSO-climate connections. (b) The correlation between the NINO-3.4 SSTA index for Dec.-Feb. and the unsmoothed divisional rainfall for Jan.-Mar. during the 30 year period 1930-1959. (c) As in b, but for the 30 year period 1965-1994. The Mississippi basin is highlighted by light gray fill. The colorbar applies to both maps. $90 \%$ significance is indicated by enhanced circles and by dashed vertical lines on the colorbar. 
Consistent with the North Atlantic mode of ME99, correlations between the AMO index and SSTA elsewhere in the world ocean are small, except for the Pacific, mainly north of $40^{\circ} \mathrm{N}$. ME99 hypothesize that the covariability in the North Pacific is passively linked to the North Atlantic through fluctuations in the tropospheric polar vortex. This, and our choice of referring to the variability as "Atlantic", are consistent with indications that the oscillation is driven primarily by interactions in the Atlantic sector and that the Atlantic thermohaline circulation is involved [Delworth and Mann, 2000; Venegas and Mysak, 2000]. However, we note that the variability is global in scope and that the presence of the signal in the North Pacific SST may augment the AMO mode itself and certainly may contribute to the climate impacts associated with the AMO, such as we describe in this paper. We also note that ME99 have found other multidecadal modes of SSTA variability in the Pacific but that they are temporally uncorrelated with the AMO variability.

The correlations of the similarly smoothed climate division rainfall with the AMO index display a robust continentalscale pattern dominated by negative correlations (Fig. 1c). Many of the $90 \%$ significant correlations, all negative, are found in the Mississippi basin. A further clustering of negative correlations occurs west of the continental divide, except for positive correlations in the Pacific Northwest. Positive regional clusters also appear in the northeast and Florida.

As a check on the seasonality of the rainfall pattern the analysis was repeated for three-month seasonal averages of the rainfall data (not shown). In all but the summer season (July-August-September) the patterns are different from Fig. 1c and have far fewer significant correlations. The summer season pattern is similar and has many significant correlations. We therefore believe that multidecadal variations in summer rainfall are mainly responsible for the observed relationship.

The temporal variabilities of rainfall are displayed for two representative hydrological provinces. The large distribution of negative correlations in the central U.S. is characterized by the area-weighted accumulation of division rainfall within the Mississippi basin (Fig. 2a). The smoothed, directly measured time series of Mississippi River outflow to the Gulf of Mexico is shown for comparison. To characterize the positive correlation in a much smaller region, we show the single Florida division 4 rainfall series (Fig. 2b), which includes the entire catchment for the Lake Okeechobee inflow in south-central Florida (Fig. 1c). We also show the estimated unmanaged Lake Okeechobee inflow computed as the difference between measured lake volume changes and the total metered outflows at sluice gates [South Florida Water Management District]. For both catchments the flow closely mimics the rainfall totals, in spite of the neglect of evapotranspiration. We note that the peak-to-peak variations are $10 \%$ and $40 \%$ of the long-term mean for the Mississippi and Okeechobee flows, respectively. The former represents a very large amount of water annually, while the latter significantly affects water management policy in the hydrologically sensitive South Florida region.

Consistent with the significant divisional correlations in Fig. 1c, these two very different hydrological regions track the phases of the AMO very closely (Fig. 1a), except for a brief period in the 1940s for the Mississippi basin. A more detailed examination of SSTA in subregions of the North At- lantic and allowing for shorter periodicities (less smoothing) does not suggest an Atlantic source for the 1940s anomaly. We can only speculate that the Mississippi basin is also sensitive to and affected by one or more of the other slow climate modes, such as occur in the Pacific sector.

\section{Changes in ENSO variability}

It is of interest to know whether the pattern of teleconnections of U.S. rainfall to tropical Pacific ENSO indices changes significantly between phases of the AMO. It was recently shown that changes in ENSO related rainfall anomalies occur with alternating phases of the Pacific Decadal Oscillation (PDO). The PDO has shorter time scales than that of the AMO [Mantua et al., 1997]. A north-south bipolar distribution of correlations between western U.S. rainfall and the Southern Oscillation Index (SOI) is stronger (more significant correlations) when east Pacific SSTA is decadally cool [McCabe and Dettinger, 1999]. During the high phase of the PDO (east Pacific warm) El Niño events exhibit a more robust pattern of wetter (drier) winters in the southern (northern) tier of the contiguous United States [Gershunov and Barnett, 1998].

To test for analogous relationships with the AMO, we first computed running 20-year correlations of the unsmoothed Mississippi basin and Okeechobee rainfall totals with the average SSTA over the NINO-3.4 index region in the equatorial Pacific $\left(5^{\circ} \mathrm{N}-5^{\circ} \mathrm{S}, 170^{\circ} \mathrm{W}-120^{\circ} \mathrm{W}\right)$. The correlations are steadily positive and significant for the Lake Okeechobee rainfall, i.e., south-central Florida is wetter (dryer) during El Niño (La Niña) years, regardless of the AMO phase (Fig. 3a). For the Mississippi basin rainfall, however, we see a very clear change (Fig. 3b). During the 1930-1960 warm phase of the AMO the rainfall had a significant negative correlation with NINO-3.4, whereas during the cool phases before and after the correlations were insignificant.

To better understand the running correlations we correlated the boreal winter NINO-3.4 index (December-JanuaryFebruary) with the winter rainfall (January-February-March) of every climate division, for two contrasting 30 year periods (Fig. 4a): 1930- 1959 (Fig. 4b) and 1965-1994 (Fig. 4c). The correlation patterns are similar in form but contrast greatly in the size of regional clusters. For the AMO warm phase, most of the eastern Mississippi basin is characterized by large negative correlations, while significant positive correlations are confined to Florida and the southwestern border with Mexico. For the more recent cool phase of the AMO, the period for which most of our present knowledge of ENSO impacts has been obtained, there is a larger distribution of positive correlations all along the southern tier states. In contrast, the coverage of negative correlations over the eastern Mississippi basin is half that of the warm phase, while the Great Plains shows a large positive cluster. The net result is that the Mississippi basin rainfall accumulation is significantly impacted by ENSO (less winter rainfall during El Niño events) during the AMO warm phase (when negative correlations dominate) but not during the cool phase (when positive correlations offset negative correlations). The changes in the continental scale pattern are not reflected in Florida rainfall, which has significant positive correlations for both phases of the AMO.

An analysis of how the AMO modulation of ENSO- connected U.S. rainfall is related to the PDO modulation in the western U.S. [McCabe and Dettinger, 1999] is beyond the 
scope of this paper. We note, however, that the PDO is characterized by shorter time scales than the AMO. Hence, both of these slow modes appear to modulate ENSO rainfall and their effects may interact in complicated ways.

\section{Discussion}

To probe the explanation for the patterns we see, we calculated the composite average distributions of $500 \mathrm{hPa}$ geopotential height from the NCEP/NCAR reanalysis [Kalnay et al., 1996] for two periods, 1949-1969 and 1970-1994, and subtracted the average for 1949-1999 (not shown). For the early period (AMO warm) the normal winter ridge-trough pattern is flattened over the northern tier of the U.S., ie., the ridge over the Pacific Northwest weakens and the trough over the northern east-central region also weakens. Over the southern tier the tendency is opposite, i.e., $500 \mathrm{hPa}$ heights tend to rise off the west coast and decrease across the southeast. This can be interpreted as a greater (lesser) frequency of winter cyclonic activity and rainfall in the northwest (east-central) while the opposite holds in the southwest (southeast). These mean tendencies are clearly reflected in the correlations between the AMO index and smoothed rainfall (Fig. 1c). They run counter to the ENSO teleconnections in the west, weakening the ENSO pattern there (Fig. 4b) while enhancing the El Niño pattern of dryness over the southern Ohio River drainage. For the later period (AMO cool) the $500 \mathrm{hPa}$ ridge-trough pattern is strengthened. This accentuates the ENSO pattern in the west and diminishes the area of dryness south of the Great Lakes (Fig. 4c).

We note that the AMO index has been increasing since about 1990 and became positive again circa 1995 . Hence, we may have once again entered a period such as 1930-1960, and global temperatures can be expected to be greater than they would be based only on greenhouse and other external forcings [Andronova and Schlesinger, 2000]. However, contrary to the general expectation of greater extratropical rainfall under greenhouse warming scenarios [Houghton et al., 1996], the effect of this new AMO warming should be to decrease annual rainfall totals over the U.S., especially over the eastern Mississippi basin. This implies that future attempts to anticipate the impact of global warming on regional rainfall may prove inaccurate if the models do not reproduce the AMO variability and its impacts. This raises the bar on the ability of coupled models to simulate the climate of the 21 st century.

The AMO-related rainfall variability has immediate practical implications for water management policies in the affected regions of the United States. For example, during the positive phase of the oscillation (1930-1964), net average annual inflow to Lake Okeechobee was about double that during the ensuing negative phase (1965-1994). This translates into a near complete reversal in water management priorities for multi-decadal periods. During the negative AMO phase, inflow to the Lake is barely enough to meet the significant water needs of south Florida and management policy must be biased in favor of water conservation. Included are the hydrological demands of the Everglades, the minimum freshwater flows required for the numerous productive estuaries that populate the Florida coastlines, the demands of agricultural industries that exploit the interior sections of south Florida, and the water supplies of the rapidly developing coastal communities. During the positive phase management priorities shift towards flood protection for the region surrounding the Lake and minimizing the undesirable ecological impacts of high water levels on the Lake's littoral zone. This often requires large discharges of freshwater through the coastal estuaries that must be managed carefully to minimize adverse effects that such discharges have on the downstream ecosystems.

Finally, it is clear both from this study and that of others that the slow variability (decadal or longer) in both northern oceans renders ENSO teleconnections nonstationary over the United States. Current methods of forecasting ENSO climate impacts are based mainly on empirical relationships involving observations taken during the recent AMO cool phase. To the extent that we continue to use empirical relationships, the shifts currently taking place might be accounted for by using earlier observations and paleoclimate findings. However, it is also clear that the best long-term solution for climate prediction is to overcome the current failure of coupled models to forecast rainfall impacts, and for the models to account for interdecadal variabilities.

Acknowledgments. We thank D. Goolsby (USGS) for providing Mississippi River data and three AOML colleagues (Drs. C. Wang, H. Willoughby and C. Landsea) for their comments. This research was funded by NOAA's Office of Global Programs (PACS GC99-024) and the Inter-American Institute for Global Change Research (IAI CRN-038).

\section{References}

Andronova, N. G., and M. E. Schlesinger, Causes of global temperature changes during the 19th and 20th centuries, Geophys. Res. Lett., 27, 2137-2140, 2000.

Delworth, T. L., and M. E. Mann, Observed and simulated multidecadal variability in the Northern Hemisphere, Climate Dynamics, 16, 661-676, 2000.

Ebisuzaki, W., A method to estimate the statistical significance of a correlation when the data are serially correlated, J. Climate, 10, 2147-2153, 1997.

Gershunov, A., and T.P. Barnett, Interdecadal Modulation of ENSO Teleconnections, Bull. Amer. Meteor. Soc., 80, 27152725, 1998.

Houghton, J.T. et al., Climate Change 1995: The Science of Climate Change, Cambridge University Press, 1996.

Kalnay, E. et al., The NCEP/NCAR 40-year reanalysis project, Bull. Amer. Meteor. Soc., 77, 437-471, 1996.

Kaplan, A., M. A. Cane, Y. Kushnir, and A. C. Clement, Analysis of global sea surface temperatures 1856-1991, J. Geophys. Res., 103, 18,567-18,589, 1998.

Kerr, R. A., A North Atlantic climate pacemaker for the centuries, Science, 288 (5473), 1984-1986, 2000.

Mantua, N.J., S.R. Hare, Y. Zhang, J.M. Wallace, and R.C. Francis, A Pacific decadal climate oscillation with impacts on salmon production, Bull. Amer. Meteor. Soc., 78, 1069-1079, 1997.

McCabe, G. J., and M. D. Dettinger, Decadal variations in the strength of ENSO teleconnections with precipitation in the western United States, Int. J. Climatol., 19, 1399-1410, 2000.

Mestas-Nuñez, A. M., and D. B. Enfield, Rotated global modes of non-ENSO sea surface temperature variability, J. Climate, 12, 2734-2746, 1999.

Schlesinger, M. E., and N. Ramankutty, An oscillation in the global climate system of period 65-70 years, Nature, 367, 723$726,1994$.

Venegas, S.A., and L.A. Mysak, Is there a dominant timescale of natural climate variability in the Arctic?, J. Climate, 13, 3412-3434, 2000.

D. B. Enfield, NOAA Atlantic Oceanographic and Meteorological Laboratory, Miami, FL, 33149 USA. (e-mail: en field@aoml.noaa.gov)

(Received December 12, 2000; revised February 16, 2001; accepted February 26, 2001.) 